\title{
Importance of Anatomical Studies on Wild Animals in Veterinary Sciences
}

\author{
Roqueline AGMF Aversi-Ferreira ${ }^{1}$, Hisao Nishijo ${ }^{2}$ and Tales A Aversi-Ferreira ${ }^{3 *}$ \\ ${ }^{1}$ College of Nutrition, Brazil \\ ${ }^{2}$ Department of Physiology, Japan \\ ${ }^{3}$ Laboratory of Biomathematics, Brazil
}

*Corresponding author: Tales Alexandre Aversi-Ferreira, Department of Anatomy, University of Alfenas, Brazil, Rua Gabriel Monteiro da Silva, 700 , Centro, block N, Alfenas, Minas Gerais, 37130-001, Brazil

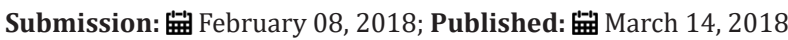

\begin{abstract}
Anatomy plays an important role in the comparative studies of different species, but it is falling into academic and scientific crisis and some researchers ignore the evidence that the current health sciences were and are dependent on the anatomical data for clinical and surgical aspects, and anatomy is the base for phylogenetic, taxonomic, evolutionary, and ethological studies. The anatomical knowledge is an indispensable aspect for the students who will encounter professional problems, as veterinarians or biologists. Nowadays, the possibility of veterinarians encountering problems in your professional work has increased due to the following situations: 1) the number of wild animals that are used as companions is increasing and 2) the constant invasion of modern society into the wild habitats has increased the number of accidents involving these animals. Therefore, sufficient anatomical knowledge is necessary for the veterinarians and biologists to execute appropriate procedures. We suggest that these professionals should be prepared with good scholar formation, where the anatomical teaching and knowledge are fundamental. Furthermore, anatomical studies on wild animals, which are scarcely published until now, are required as reptiles and amphibians are increasingly used as companion animals in the modern society.
\end{abstract}

\section{Opinion}

Anatomy is the branch of science that studies the body of an organism [1]. It has a rich history in the field of health sciences. It is a basic discipline in the field of human and animal health, and is indispensable for the students of veterinary and medical sciences who require sufficient knowledge for clinical work [2]. It plays an important role in the comparative studies of different species [3]. Thus, anatomy, a pre-clinical discipline, is fundamental in all health science courses, and is considered the basis of morphological studies [4]. It is a discipline that must be learned in its entirety [5].

However, this branch is falling into academic and scientific crisis [6]. Nowadays, many colleges are decreasing the curriculum time [7], mainly by reducing the time allocated for basic science disciplines [4]. In this milieu, teaching traditional anatomy based on topography, didactic lectures, and dissection with tuition have been replaced by a multiple range of specific studies, such as problem-based workshops, use of computerized or plastic models of the body, and many other teaching tools [8,9]. In some schools, dissected cadaver-based anatomy is no longer taught [9].

Some researchers do not consider the importance of anatomical sciences [6]. They ignore the evidence that [1] the current health sciences were and are dependent on the anatomical data for clinical and surgical aspects, and [2] anatomy is the base for phylogenetic, taxonomic, evolutionary, and ethological studies [10-12]. As comparative anatomy of many species has not been established [13], it is difficult [1] to construct an evolution tree, [2] to make a correct taxonomic analysis, and [3] for veterinarians to apply the correct clinical/surgical intervention when they receive a wild animal in a clinic.

Many researchers and educators have published papers indicating the importance of dissection as a teaching resource [715]. The major advantage of dissection practice is that it allows students to build their knowledge themselves because dissection requires the students to associate the previous knowledge acquired in classes, text books, and observations in the atlas with the dissected structures [16]. The students then associate the visual, tactile, and kinesthetic experiences together with the manual activities [13], which stimulates reasoning and reflections to construct their own reality.

Accordingly, a good teaching of anatomy would allow professionals to be prepared to receive an unknown animal and offer a better treatment, even if the animal is listed as endangered. Kindlovitsin the book "Clinical and Therapeutics in Neotropical Primates" has cited previous studies on clinical and surgical applications in capuchin monkeys; however, only a few anatomical data have been cited, mainly because data on the capuchin monkeys in 1999 and before were scarce than that are currently available. 
Under these circumstances, it is difficult for the professionals to choose the best surgical access and perform the correct clinical procedures in general. Although the capuchins are the most common neotropical primates in the veterinary clinics in Brazil and South America [17], the anatomy of the capuchins is still incomplete [18].

There are many wild animals whose anatomy is even more incomplete than the that of capuchin monkeys. For instance, only a few studies have investigated the anatomy of anteaters [19-22], especially the giant anteaters, which are at a risk of extinction. When veterinarians receive this animal in a clinic, they would have problems to decide a correct and precise treatment, especially during surgical emergency.

The anatomical knowledge is an indispensable aspect for the students who will encounter professional problems, as veterinarians or biologists. Nowadays, the possibility of encountering such problems has increased due to the following situations: 1) the number of wild animals that are used as companions is increasing [23] and 2) the constant invasion of modern society into the wild habitats has increased the number of accidents involving these animals [24]. According to Grant, Nontrose and Wills [23], exotic birds, reptiles, amphibians, and exotic mammals have been increasingly used as companion animals during the last two decades. The recent situations indicate a tendency for increase in the number of wild animals in veterinary clinics, and the veterinarians must be prepared for these situations. Anatomical teaching will play an important role if the students are appropriately prepared with good scholar formation.

The increasing use of wild animals as companions and increasing invasion of modern society into the wild habitats have increased the incidences where the veterinarians and biologists encounter these animals. Therefore, sufficient anatomical knowledge is necessary for the veterinarians and biologists to execute appropriate procedures. We suggest that these professionals should be prepared with good scholar formation, where the anatomical teaching and knowledge are fundamental. Furthermore, anatomical studies on wild animals, which are scarcely published until now, are required as reptiles and amphibians are increasingly used as companion animals in the modern society $[23,25]$.

\section{References}

1. Garder E, Gray D, O'Rahilly R (1978) Anatomia - estudo redional do corpo humano. Guanabara, Rio de Janeiro, Brazil ( $4^{\text {th }}$ edn).

2. Nobrega KSDA, Tavares R (2008) A aprendizagem de anatomia: a utilização de mapas conceituais como uma ferramenta instrucional. XXII Congresso Brasileiro de Anatomia, Belem.

3. Aversi-Ferreira RA, deSouza V, Tomaz C, Aversi-Ferreira TA (2014) Comparative anatomy of the pelvic vessels in the bearded capuchin (Sapajus libidinosus) and baboons, apes and modern humans. Folia Primatol (Basel) 85(4): 252-264.

4. Aversi-Ferreira TA, Nascimento GNL, Vera I, Lucchese R (2010) The practice of dissection as teaching methodology in anatomy applied to medical education. Int J Morphol 28(1): 265-272.

5. Disnmore CE, Daugherty S, Zeitz HJ (1999) Teaching and learning gross anatomy: dissection. Prosection, or both of the above? Clin Anat 12(2):
$110-114$.

6. PfrimerGA, AbreuT, SouzaVieraV, SoaresNP, Aversi-Ferreira RAGMF et al. (2012) Historic and teaching aspects of anatomy and Cebus genus role in contemporary anatomy. Int J Morphol 30(2): 607-612.

7. Leung KK, LuKS, Huang TS, Hsieh BS (2006) Anatomy Instruction in Medical Schools: Connecting the Past and the Future. Advances in Health Sciences Education 11(2): 209-215.

8. Aziz MA, Mckenzie JC, Wilson JS, Cowie RJ, Ayeni SA, et al. (2002) The human cadaver in the age of biomedical informatics. Anat Rec 269(1): 20-32.

9. Biasutto SN, Caussa LI, Del Rio LEC (2006) Teaching anatomy? Cadaver vs. computer. Ann Anat 188(2): 187-190.

10. Flores BGM (2006) What the dissection meaning for medical students. Int J Morphol 24(4): 575-580.

11. Ankel-Simons F (2000) Primate anatomy: an introduction. Academic Press, Orlando, USA, p. 724.

12. Aversi-Ferreira RAGMF, Abreu T, Pfrimer GA, Silva SF, Ziermann JM, et al. (2013) Comparative anatomy of the hind limb vessels of the bearded capuchins (Sapajus libidinosus) with apes, baboons, and Cebus capucinus: with comments on the vessels' role in bipedalism. BioMed Res Int 2013: $1-15$.

13. Aversi-Ferreira TA, Lopes DB, Reis SM, Abreu T, Aversi-Ferreira RAGMF, et al. (2009) Practice of dissection as teaching methodology in anatomy for nursing education. Braz J Morphol Sci 26(3-4): 151-157.

14. McLachlan CJ, Patten D (2006) Anatomy teaching: ghosts of the past, a present and future. Med Educ 40(3): 243-253.

15. Sugand K, Abrahams P, Khurana A (2010) The anatomy of anatomy: a review for its modernization. Anat Sci Educ 3(2): 83-93.

16. Aversi-Ferreira TA, Diogo R, Potau JM, Bello G, Pastor JF, et al. (2010) Comparative anatomical study of the forearm extensor muscles of Cebus libidinosus (Rylands et al. 2000; Primates, Cebidae), modern humans, and other primates, with comments on primate evolution, phylogeny, and manipulatory behavior. Anat Rec (Hoboken) 293(12): 2056-2070.

17. Aversi-Ferreira RAGMF, Marin KA, Carneiro e Silva FO, Aversi-Ferreira TA (2011) Comparative anatomy of the thigh nerve of Cebus libidinosus (Rylands et al. 2000) manipulatory behavior and tool use. PLoS One 6(7):e22165.

18. Aversi-Ferreira TA, Maior RS, Carneiro-e-Silva FO, Aversi-Ferreira RAGMF, Tavares MC, et al. (2011) Comparative anatomical analyses of the forearm muscles of Cebus libidinosus (Rylands et al. 2000): manipulatory behavior and tool use. Plos One 6(7): e22165.

19. Taylor BK (1978) The anatomy of the forelimb in the anteater (Tamandua) and its functional implications. J Morphol 157(3): 347-367.

20. Naples V (1999) Morphology, evolution and function of feeding in the giant anteater (Myrmecophaga tridactyla). J Zool 249(1): 19-41.

21. Gambaryan PP, Zherebtsova OV, Perepelova AA, Platonov VV (2009) Pes muscles and their action in giant anteater Myrmecophaga tridactyla (Myrmecophagidae, Pilosa) compared with other plantigrade mammals. Russian J Theriol 8(1): 1-15.

22. Souza PR, Cardoso JR, Araujo LB, Moreira PC, Cruz VS, et al. (2014) Gross anatomy of the brachial plexus in the giant anteater (Myrmecophaga tridactyla). Anat Histol Embryol 43(5): 341-345.

23. Grant RA, Montrose VT, Wills AP (2017) Should We Be Keeping Exotic Pets? Animals (Basel) 7(6): 47

24. Rowden PJ, Steinhardt DA, Sheehan MC (2008) Road crashes involving animals in Australia. Accident Analysis and Prevention 40(6): 18651871.

25. Kindlovits A (1999) Clínica e terapêutica em primatas neotropicais. UFJF Press, Juiz de Fora, p. 535 
Creative Commons Attribution 4.0 International License

For possible submissions Click Here

Submit Article
APDV $\quad$ Approaches in Poultry, Dairy \& Veterinary Sciences

\section{Benefits of Publishing with us}

- High-level peer review and editorial services

- Freely accessible online immediately upon publication

- Authors retain the copyright to their work

- Licensing it under a Creative Commons license

- Visibility through different online platforms 